\title{
Políticas públicas de promoción de la autogestión cooperativa de la Alianza Cambiemos
}

Promoting cooperative self-management through public policies: the Alianza Cambiemos

Juan Pablo Hudson

Conicet / Instituto de Investigaciones Gino Germani

juanpablohudson@hotmail.com
Fecha de recepción:

7.3.18

Fecha de aceptación: 23.618

\section{Resumen}

Se analizan en este artículo las continuidades y rupturas introducidas durante 2016 y 2017 por el gobierno nacional en la implementación del Programa de Trabajo Autogestionado (Ministerio de Trabajo) y del Programa de Ingreso Social con Trabajo (Ministerio de Desarrollo Social). La Alianza Cambiemos utilizó una sólida estructura estatal de creación de empleo a través del asociativismo que había permitido asistir, entre 2003 y 2015, a informales y desempleados crónicos. En la primera mitad del mandato incrementó los presupuestos, eliminó el requisito de que los reclamantes se organicen en cooperativas para obtener subsidios, exaltando la figura del individuo emprendedor, y fortaleció el poder económico-administrativo de las organizaciones sociales. El objetivo fue sostener la asistencia a los excluidos crónicos y contener eventuales conflictos sociales en un crítico escenario económico inducido por sus propias políticas.

Palabras clave: políticas públicas - autogestión empleo - inclusión social - organizaciones sociales.

\section{Abstract}

This article analyzes continuities and ruptures introduced by the alliance Cambiemos in the implementation of the 
Self-Managed Work Program (Ministry of Labor), and the Social Income with Work Program (Ministry of Social Development). Cambiemos found a solid state structure of job creation through the associativism approach that allowed, between 2003 and 2015, to attend informal and chronic unemployed. In the first half of the mandate, it increased the budgets, eliminated the requirement to organize the unemployed in cooperatives in order to access to subsidies, and strengthened the economic-administrative power of social organizations. The objective was to support the assistance to the chronically excluded and to contain possible social conflicts in a critical economic scenario induced by their own policies.

Key-words: public policies - self-management - employment - social inclusion - social organizations.

\section{Introducción}

Este artículo desarrolla un estudio en profundidad del Programa de Trabajo Autogestionado (PTA), perteneciente a la Secretaría de Empleo del Ministerio de Trabajo, Empleo y Seguridad Social (MTEySS) y del Programa de Ingreso Social con Trabajo (PRIST), del Ministerio de Desarrollo Social de la Nación (MDSN), cuya aplicación territorial se realiza a través del "Plan Argentina Trabaja” (PAT) y del plan "Ellas Hacen” (EH).

El cambio de gobierno nacional acontecido en diciembre 2015 puso fin a tres períodos consecutivos de lo que se denominó la nueva gobernabilidad (Colectivo Situaciones 2009) o "gobiernos progresistas" (Sader 2012). El triunfo electoral de la coalición Cambiemos abrió interrogantes en torno a cuáles serían los lineamientos políticos que se desarrollarían en materia económica, financiera, institucional, social y laboral. En el caso puntual de las políticas de subsidios económicos hacia los sectores populares la incertidumbre fue todavía más marcada que en otras áreas. Recordemos que durante el período 2003-2015 se montó una sólida estructura de transferencia de recursos fiscales hacia estos segmentos de la población a través de programas impulsados desde MTEySS y el MDSN.

El artículo se centra en las continuidades y cambios en las políticas de generación de empleo e inclusión social a través del impulso al cooperativismo y la autogestión. Durante la última década se desarrollaron múltiples investigaciones académicas en torno a la relación que los gobiernos nacionales entablaron en el período 2003-2015 con los 
movimientos sociales que habían resistido entre 1995-2003 las peores consecuencias de las políticas neoliberales. Los principales movimientos fueron los de desempleados (MDD), las empresas recuperadas por trabajadores (ERT) en los grandes centros urbanos, y los campesinos indígenas (MCI) en el mundo rural.

La emergencia de los MDD acaparó la atención en las investigaciones académicas. No fue casual entonces que aquella proliferación de trabajos se extendiera después de 2003 a través de estudios sobre la compleja relación entre los sucesivos gobiernos nacionales (Néstor Kirchner 2003/2007; Cristina Fernández 2007/2011 y 2011/2015) y las principales organizaciones de trabajadores desocupados. Una lectura minuciosa de esa bibliografia muestra diferentes líneas de análisis necesarias para este trabajo. La lectura más extendida afirma que ese vínculo se redujo a la cooptación, institucionalización y subordinación de las organizaciones por parte de los gobiernos (Svampa 2003 y 2005; Svampa y Pereyra 2004; Zibechi 2008; Fornillo 2008; Massetti 2009); en cambio otra hipótesis relevada da cuenta de un reflujo y una desmovilización con recorte de la autonomía ante una nueva legitimación del Estado como regulador de lo social (Rajland y Campione 2006; Pereyra, Pérez y Schuster 2009) luego de la crisis de representación padecida por el sistema político a nivel institucional acontecida a principios del siglo XXI. Se sumó una tercera corriente que propuso salir del recurrente análisis a partir del binomio autonomía-cooptación/institucionalización para pasar a pensar en términos de ambivalencias y tensiones permanentes, a la vez que advertía sobre la imperiosa necesidad de no enfocar la mirada únicamente desde arriba para pasar a incorporar las perspectivas y cálculos de las bases sociales de cada organización (Schuttenberg 2014; Natalucci 2014; Perelmiter 2010).

La situación bibliográfica fue otra en el caso del estudio de los vínculos entre el kirchnerismo y las ERT. El peso del análisis recayó en el desglose de las políticas neoliberales impulsadas en la década de 1990 y en el interrumpido gobierno de Fernando De la Rúa (Rebón 2004 y 2007; Deux Marzi y Escobedo 2005; Fernández 2006; Gracia y Cavaliere 2007; Salgado 2012). Se las sindicó con precisión como las causantes de las quiebras financieras de las empresas y fábricas que fueron posteriormente recuperadas por los obreros; otros trabajos textos abordaron la intensa discusión desatada en los movimientos sectoriales sobre si la figura más adecuada para adoptar después de las recuperaciones era la estatización con control obrero o el desarrollo de cooperativas autogestivas (Cafardo y Domínguez Font 2003; Rebón 2004; Fajn 2003; Magnani 2003; Heller 2004).

Pero lo que no encontró un desarrollo equivalente fue el estudio de la nueva etapa que se abrió en 2003, a pesar de que estos gobiernos dieron inmediatas muestras de un cambio de perspectiva en la relación con las cooperativas obreras ya constituidas y también con los nuevos casos que fueron surgiendo en el período. La reducida bibliografia que se ha ocupado con detenimiento de esta problemática (Allegrone, Fernández Álvarez y Partenio 2007; Hudson 2011a, 2016, 2017; Programa Facultad Abierta 2010 y 2014; Pico, 2015), se 
concentró en los nuevos modos de gestión estatal puestos en marcha a través de programas específicos hacia el sector. Estos trabajos colocaron el acento en la ruptura con tres tendencias previas: la represión, la indiferencia y el rechazo; al tiempo que se destaca el proceso a través del cual las cooperativas comenzaron a ser financiadas, a la vez que el propio gobierno nacional fue el que impulsó la recuperación de empresas como política estatal.

Por último, registramos en la bibliografia referida al estudio de planes de promoción del asociativismo como el Programa de Inclusión Social con Trabajo (PRIST) tres líneas relevantes para este artículo. Primero, un conjunto de trabajos (Lo Vuolo 2010; Giraudo 2013; Hopp 2015 y 2016; Natalucci 2012; Vuotto 2011) que enfatizan en el carácter inducido de las cooperativas creadas en el marco del Plan Argentina Trabaja (PAT). Malena Hopp introduce, desde esta perspectiva, un valioso concepto: el PRIST impone desde arriba una asociatividad forzada (Hopp 2015: 220). En una misma dirección, Mirta Vuotto ya había anticipado este análisis cuando separó entre cooperativas integradas, reivindicativas e inducidas por el Estado (Vuotto 2011). La segunda hipótesis relevante para nuestras mis investigaciones se concentra en la denuncia del carácter clientelar de estos planes (Giraudo 2013; Malandra 2013; De Sena y Chahbenderian 2012; Mainero 2015). Allí podríamos separar, por un lado, entre quienes sentencian como negativas a este tipo de políticas públicas por carecer de un carácter universal (Abramovich y Pautassi 2009, De Sena y Chahbenderian 2012); y por otro, aquellas investigaciones que enfatizan que toda política social implica niveles de conflictividad entre las instancias gubernamentales y los beneficiarios, sean individuos u organizaciones. En el caso del PRIST, este segundo enfoque señala los constantes conflictos entre las organizaciones sociales, los municipios y el gobierno nacional (Natalucci 2012; Perelmiter 2016; Kasparian, 2017). Finalmente, existe una tercera línea (Hopp 2015 y 2016; Hintze 2007; Giraudo 2013) que, a partir de los postulados teóricos de la economía social y solidaria, afirma que no existe en nuestro país un apoyo estatal genuino e integral a este tipo de economía. Muestra de ello es que el PRIST fue impulsado desde el MDSN y no desde el MTEySS y/o el de la Producción.

Los materiales empíricos que utilizaremos tienen múltiples fuentes. Una primera es la investigación de corte cualitativo que hemos realizado en ERT del Gran Rosario entre 2004 y 2017. Esto incluye el estudio -entrevistas en profundidad, observaciones no participantes, encuestas- de las cooperativas obreras, incluida su relación con los gobiernos nacionales. La segunda fuente es la realización de 15 entrevistas a funcionarios del MDSN y el MTEySS durante 2016 y 2017. Se suman fuentes secundarias como el estudio de presupuestos oficiales, leyes, decretos y documentos internos de los ministerios antes nombrados.

Finalmente, vale aclarar que el objetivo es comprender exclusivamente desde las perspectivas del actual gobierno nacional las rupturas y continuidades en la puesta en marcha de políticas públicas de impulso al asociativismo y la autogestión. En el caso de las interpretaciones de los miembros de las cooperativas y de las de las organizaciones sociales, 
serán el eje central de una segunda etapa de indagación (actualmente en curso). Tan solo se ha recurrido, para reconstruir pasajes puntuales de la historia de la Confederación de Trabajadores de la Economía Popular, a materiales publicados por esta organización social.

\section{Un modelo autogestivo estatal}

El presidente Néstor Kirchner (2003/2007) se propuso reconstruir una capacidad de gobernabilidad fuertemente dañada por las multitudinarias protestas callejeras y los significativos niveles de autoorganización social alcanzados a inicios de este nuevo siglo. Hubo dos epicentros, previos a su gestión: las revueltas del 19 y 20 de diciembre de 2001 que pusieron fin a la presidencia de Fernando de la Rúa; y las movilizaciones de repudio al asesinato de los militantes sociales Maximiliano Kosteki y Darío Santillán durante un corte de ruta ocurrido el 26 de junio de 2002, una de las razones principales que obligaron a adelantar las elecciones al entonces presidente interino Eduardo Duhalde.

Los movimientos de empresas recuperadas, de desempleados y de campesinos (entre otros) habían puesto en marcha proyectos productivos que permitieron la subsistencia de vastos sectores de la población excluidos del mercado de trabajo y de cualquier amparo estatal. Desde el nuevo gobierno se tornaba indispensable entablar un diálogo posible con estos movimientos, a la vez que transformarlos en objeto de asistencia y, simultáneamente, de investigación. Había en ellos valiosos saberes labrados en un contexto de severa precariedad, desocupación y pobreza.

Una muestra contundente de esa investigación impulsada por el MTEySS es la generación entre 2004 y 2015 de constantes jornadas de debate sectoriales, ${ }^{1}$ la apertura de diálogos formales e informales semanales y la participación de universidades e institutos de investigación en la elaboración de diagnósticos técnicos. El primer objetivo fue la gestación de un sólido corpus teórico sobre los desafios que conlleva autogestionar la producción bajo condiciones precarias. El segundo la creación de un modelo de gestión estatal propio capaz de incubar experiencias cooperativas entre los desempleados e informales crónicos.

Los primeros programas de promoción del asociativismo se lanzaron en 2004 en el MTEySS. Se los anunció como una estrategia coyuntural al calor de los efectos de una crisis todavía persistente. Pero su expansión durante todo el período 2004-2015 demostró que, a pesar del relevante crecimiento de la industria y la creación de empleos, la reconstrucción de una nueva sociedad salarial no era posible. Las mutaciones en el mundo del trabajo impuestas por la economía de mercado ya no tenían retorno. El abrupto descenso del desempleo entre 2003 y 2015 se debió a una efectiva revitalización de ciertas ramas de la industria (con la generación de cinco millones de puestos de trabajo), ${ }^{2}$ aunque también, indispensablemente, a una expansiva política de subsidios que permitió el sustento de aquellos segmentos de la población considerados excluidos crónicos. 
El Programa de Trabajo Autogestionado (PTA) fue creado en la Secretaría de Empleo (MTEySS) para distribuir subsidios y estudiar las formas de funcionamiento de las ERT. De esta manera se lo presentaba en un documento interno de 2004:

El Programa de Trabajo Autogestionado surge como una respuesta concreta a diversas demandas de apoyo que venían realizando ex-empleados de empresas y fábricas implicados en procesos de recuperación de plantas productivas y fuentes de trabajo. [...] Desde el comienzo mantuvimos contacto con las organizaciones que agrupan a las empresas y fábricas, así como con trabajadores que se acercaban espontáneamente, con el objeto de estructurar un programa acorde a las demandas y necesidades de los destinatarios.

(MTEySS 2004).

Seis años más tarde, este mismo Programa anunciaba un giro relevante: incluiría también entre sus beneficiarios a otros emprendimientos siempre que cumplieran con el modelo de autogestión asociativa:

Frente a este universo y experiencias heterogéneas, que implicó que durante la crisis y primeros años post crisis el Ministerio de Trabajo jugara un rol de gestor de la política social dando respuestas a proyectos de trabajadores desocupados que surgían claramente como alternativas frente a la crisis, el desafío actual consiste en la asimilación del concepto del "trabajo autogestionado en forma asociativa" como una alternativa en el mundo del trabajo. [...] la política sustentada sobre el empleo como eje articulador de la vida de la ciudadanía y del destino económico del país requiere incorporar la consolidación de los procesos protagonizados por los trabajadores: autoempleo, emprendedorismo y trabajo autogestionado asociativo en el desafio del "pleno empleo" para la Argentina actual y futura. (MTEySS 2010).

La primera hipótesis de este apartado es la siguiente: cumplida una etapa inicial de estudio, el MTEySS logró construir un modelo autogestivo propio para incubar proyectos asociativos post-salariales protagonizados por informales y desempleados. No se trató de conocer e impulsar el cooperativismo, tal como ya lo promovía el Banco Mundial o el Fondo Monetario Internacional en la década del noventa (Svampa 2003). Se trató de replicar un tipo de funcionamiento específico que habían conseguido los obreros 
de las empresas recuperadas. La segunda hipótesis es que se trató de estudiar primero y traducir al lenguaje estatal después un tipo específico de cooperación desde abajo que fue capaz de poner en funcionamiento emprendimientos productivos prácticamente sin capital financiero, es decir, bajo condiciones precarias.

Hacia finales de 2013 el número de proyectos incubados por el PTA había crecido por encima de las ERT, sector para el cual se había creado en forma exclusiva el área. De un total de 786 unidades productivas subsidiadas, 468 (60\%) no habían tenido su origen en la recuperación de empresas en quiebra (MTEySS, 2013).Al cierre del 2015 ese porcentaje había crecido hasta el 72\%, tal como lo indica el último documento emitido por el Programa. De un total de 1249 unidades productivas autogestionadas subvencionadas, 350 fueron ERT y 899 no tenían su origen en una recuperación (MTEySS 2015).

Entre 2004 y 2015 se asistió a 43.000 trabajadores de 1249 unidades productivas a través de la línea 1 de ayuda económica individual por un total de $\$ 411.347 .800$. Se sumaron también alrededor de treinta millones de pesos en concepto de compra de materia prima e insumos, seguridad e higiene y apoyo técnico y económico (MTEySS 2015). ${ }^{3}$

En el último documento de balance se explicita también cuáles fueron los sectores a los que se dirigieron sus políticas: las ERT, las empresas autogestionadas por trabajadores como formalización de procesos de producción de bienes y/o prestación de servicios de autogestión asociativa preexistente y las empresas autogestionadas creadas en el marco de la representación sectorial y territorial de organizaciones sociales de base, integradas por colectivos de trabajadores de alta vulnerabilidad social y desocupación de larga trayectoria (MTEySS 2015); así como "un conjunto de cooperativas creadas a instancias del Estado para fomentar su participación en programas públicos, gran parte de ellos concebidas como medidas contracíclicas para sostener empleo” (MTEySS 2015).

Este último sujeto muestra que, en línea con nuestra hipótesis, los proyectos incubados por el PTA se basaron en una traducción estatal de las experiencias autogestionarias sostenidas por las ERT. Fue una de las estrategias principales puestas en marcha en el período 2003-2015 para generar trabajo e ingresos bajo condiciones post-salariales allí cuando se comprobó que la dependiente estructura industrial de la Argentina no sería capaz de generar empleo en blanco para una porción significativa de la población económicamente activa. Insistimos con la utilización del término traducción porque deja de lado extendidas hipótesis binarias que interpretaron a este tipo de políticas como mera cooptación o institucionalización de los movimientos sociales. 


\section{Cambios en la autogestión}

Una hipótesis que desplegaremos afirma que Cambiemos encontró una vasta estructura estatal de impulso al empleo cooperativo mediante la cual se asistió durante el período 2003-2015 a la población considerada como sobrante por el mercado de trabajo formal. A esos inempleables (Natalucci 2012; Scarfó, Highton y Hopp 2009) se les exigió asociarse y poner en marcha emprendimientos cooperativos que habían sido aplicados con relativo éxito por las ERT y los MDD. El gobierno de Cambiemos utilizó estas políticas públicas preexistentes en el MTEySS y en el MDSN para atenuar el impacto de la recesión provocada en los sectores populares y contener eventuales conflictos sociales. Pero aplicó cambios sustanciales que serán indagados en los próximos apartados.

En este sentido, el inicio de la gestión en diciembre de 2015 generó incertidumbre sobre un posible recorte del presupuesto del PTA o incluso sobre su eventual cierre. Sin embargo, en las entrevistas realizadas con funcionarios del MTEySS durante 2016 y 2017, se afirma que hubo un "crecimiento presupuestario geométrico”. Si bien el área no publica ni deja trascender cifras de lo ejecutado, la reconstrucción cualitativa efectuada en el área da cuenta de una relevante transferencia de subsidios a las cooperativas:

(desde la asunción del presidente Mauricio Macri) nosotros no tenemos restricciones presupuestarias. No hubo recorte y aumentamos los montos bastante más (...). (...) Ahora tenemos una instancia previa que es la de factibilidad presupuestaria, que nos dicen si hay presupuesto o no, hasta el momento nunca nos rechazaron nada (Funcionario 1 MTEySS).

Nosotros en 2016 ejecutamos el mismo presupuesto que en los diez años precedentes. Esa es la magnitud presupuestaria con la que cuenta el Programa a partir del nuevo gobierno. Podemos incluir múltiples críticas a la nueva gestión, como la mirada que tienen sobre la economía social o la popular, que es la que más utilizan, sus criterios empresariales, etc., pero nuestras partidas crecieron fuertemente en estos dos primeros años.

(Funcionario 5 MTEySS).

El ajuste del Estado no alcanzó a este área clave de promoción de la autogestión asociativa. El crecimiento presupuestario revela que se lo consideró, al menos para la primera mitad del mandato, un programa estratégico en el contexto económico recesivo, caracterizado por una pronunciada baja del consumo interno, la apertura de importaciones y los contantes 
aumentos del valor de los servicios públicos esenciales (luz, agua, gas) y de las materias primas. En tal sentido, la crítica situación industrial, en especial de la pequeña y mediana empresa que comercializa en el mercado interno, ha motorizado masivas demandas de subsidios por parte de ERT y de otros emprendimientos asociativos. Fundamentalmente se solicita el reingreso en la mencionada Línea 1 de complemento de los ingresos de cada trabajador. Una funcionaria del área lo ejemplifica a partir de casos concretos:

(...) las cooperativas con las que veníamos de un largo tiempo de asistencia y de acompañamiento ya no necesariamente a partir de aportes sino de diálogo, y que por ahí nos consultaban cuando tenían que hacer cosas con otras instituciones para ver qué nos parecía (...), otra vez cayeron en una situación de crisis. (...) vos tenés una cooperativa de la rama textil, por ejemplo, que es guau y entra otra vez a necesitar línea 1 porque están en una situación de crisis porque les cayó el $40 \%$ de la producción. (Funcionaria 2 MTEySS).

En resumen, se produjo un nítido crecimiento presupuestario del Programa pero en el marco de un también sostenido aumento de la demanda de ayuda financiera por parte de cooperativas que ingresaron nuevamente en períodos de crisis.

\section{Economía popular y social}

La diferencia entre economía popular y economía social (ver Coraggio, 2011) podría limitarse a un plano retórico. Incluso ambos términos podrían utilizarse como sinónimos. Sin embargo, el trabajo de campo evidencia una tensión manifiesta al interior del actual gobierno entre ambas concepciones, que tiene consecuencias en los modos de comprensión y gestión de sus políticas públicas de impulso del asociativismo.

Funcionarios del PTA afirman que la concepción más extendida desde 2016 es opuesta a los postulados sobre la economía social que el área sostuvo durante el período 2004-2015. Así lo expresan:

Para esta gestión la economía popular es economía informal, es la economía de subsistencia. Para las autoridades cuando vos hablás de una cooperativa que tiene actividad económica, balance, que paga sus impuestos, que tiene máquinas y una sede productiva, no es economía popular. $Y$ la autogestión asociativa es economía popular en tanto sea precaria. Y el objetivo es formalizar esa economía, 
que no quiere decir potenciarla, es como emprolijarla (Funcionario 1 MTEySS).

Por el contrario, desde su surgimiento, el PTA pretendió constituir un incipiente tercer sector con base en tres actores productivos: las ERT, los emprendimientos colectivos a los cuales colaboraba en formalizar mediante inyección de fondos, y proyectos autogestivos incubados directamente por el área. De acuerdo a un documento emitido en 2013:

(...) las empresas recuperadas y otros esquemas de autogestión constituyen una realidad que "llegó para quedarse" luego de la crisis de 2001-2002 y la posterior fase expansiva. En ese marco, por su indudable importancia económica y social, se destaca la relevancia que estas entidades se integren a políticas de Estado que hagan eje en lo productivo y la creación de empleo desde una perspectiva sustentable en el mediano y largo plazo.

(MTEySS 2013).

Sumemos un extenso testimonio surgido de una entrevista con una funcionaria, en la que se explicitan los objetivos históricos del Programa:

(...) nosotros tenemos una perspectiva conceptual de que en realidad el trabajo en relación de dependencia, (...) está bastante demodé. En el sentido de que hay un trabajo fordista, que hay una empresa y uno trabaja toda la vida en la empresa. Pero en occidente se vienen dando otras figuras del trabajo (...). Dentro de todo ese plexo entra la economía social (...). A nosotros lo que nos interesa es fortalecer en la base los conceptos institucionales del trabajo asociativo. Por eso estamos empezando a trabajar con proyecto formativos que tengan que ver con esto: nosotros sabemos que ustedes trabajan juntos desde la informalidad hace un montón de tiempo, bueno, formalizate, tené los papeles, generate un plan de negocios, buscá liquidez financiera, (...). (...) Al mismo tiempo, hacia adentro sabemos que la economía social (...) tiene su propio mercado y se puede fortalecer desde ahí. (Funcionaria 1 MTEySS).

Si bien el PTA se propuso diferenciar la economía social de una mera economía de subsistencia, esto no significa que dicha perspectiva haya sido una política extendida en 
los tres gobiernos kirchneristas. Durante estas administraciones la autogestión cooperativa también se concibió, como lo hemos mencionado, como una vía de transferencia de ingresos a los trabajadores informales y desocupados. La mayor muestra fue la puesta en marcha del Programa de Ingreso Social con Trabajo (PRIST) en 2009, cuando ya se sentían las consecuencias de la crisis financiera internacional.

Los funcionarios de Cambiemos admiten en las entrevistas las limitaciones estructurales del mercado de trabajo en la Argentina y, en ese contexto, la vital importancia que le asignan al asociativismo.

Es un consenso bastante grande que el mercado formal tradicional no va absorber a la masa de personas desempleadas que tenemos en la Argentina. Eso es así. Y que no es un tema de ecuación de cuánto crecer por año. Es un tema del diseño del sistema capitalista. (...) Algo muy positivo es que la economía social, la autogestión, lo colectivo, ganó legitimidad.(...) Hoy nadie te va a discutir que la autogestión no es buena o no sirve y no tiene sentido (Funcionario $1 \mathrm{MDSN}$ ).

Sin embargo, la estrategia en 2016 y 2017 consistió en diferenciar, utilizando criterios empresariales, entre cooperativas subsidiadas que cuentan con capacidad de empleabilidad y comercialización, y aquellas que se reducen meramente a ser canales de transferencia de recursos para la contención de los individuos. Consultado sobre la reducción de la economía popular a una economía de subsistencia, un funcionario explicita su rechazo:

No, no estoy de acuerdo. Incluso en los diálogos que tenemos con las organizaciones, siempre se centran, salvo con los programas de transferencia condicionada, en cómo promovemos lo productivo, cómo promovemos la formalización, que se estructuren las unidades productivas para ser competitivas en el mercado, para que el asociativismo tenga fuerza real, tenga expresión. Nosotros seguimos creyendo que lo que necesitamos es estructurar las unidades productivas to mejor posible para que desde la lógica de la economía social compitan en el mercado (...). (Funcionario 4 MDSN).

En otra entrevista un funcionario explicita una diferencia precisa entre los alcances de la economía popular y la economía social desde la perspectiva de la nueva gestión: 
Para hablar de economía social necesariamente tenés que hablar de unidad productiva para ver cómo se organiza esa producción. Y para mí en la economía popular más bien mirás al sujeto, al individuo, al trabajador. Con lo cual puede haber experiencias, actores, o redes, que sean ambas cosas, y otras que sean una de las dos cosas y no la otra. Entonces para mí economía social es todo lo que tiene que ver con la acción colectiva de un proyecto asociativo productivo. Llamando productivo a cualquier cosa que implique la reproducción ampliada de los medios de vida de sus integrantes. El caso típico es una cooperativa de trabajo. Es el caso que cierra por todos lados. Es el ejemplo perfecto. (Funcionario $2 \mathrm{MDSN}$ ).

El testimonio afirma que financiar la economía social es promover la producción para que las cooperativas operen en el mercado con mayores oportunidades. Un ejemplo (a pesar de su nombre) es la flamante Subsecretaría de Economía Popular creada al interior de la Secretaría de Economía Social (MDSN), cuyos montos de financiamiento van desde los 500 mil pesos a los 8 millones. Por el contrario, si la economía popular refiere a sujetos es porque para el gobierno el único objetivo es que los subsidios colaboren en la subsistencia de trabajadores empobrecidos o desocupados. De allí la eliminación del requisito de organizarse como cooperativa en el caso del PRIST.

Pero si retomamos la discusión actual en el PTA, los testimonios revelan una tensión: si los criterios para evaluar la sustentabilidad de las cooperativas deben ser empresariales o si la economía social puede utilizar parámetros propios. Los principales funcionarios del PTA consideran inviable el uso de criterios empresarios para el seguimiento y evaluación a los emprendimientos que reciben subsidios, desde las ERT a pequeños proyectos incubados por el MTEySS:

Lo sustentable depende de cómo se lo interprete. (...) Porque si yo te mando a un proyecto de la economía popular y le vas a aplicar categorías de sustentabilidad que también le aplican a una empresa privada, por más buena que sea esa cooperativa, ninguna es sustentable, ninguna tiene márgenes de sustentabilidad que le permitan diversificar la producción si no es con apoyo estatal. (Funcionario 3 MTEySS). 
Una funcionaria del MDSN sostiene una perspectiva similar en el caso del PRIST:

Una palabra que incorporó esta nueva gestión es la empleabilidad. (...) O sea, vos municipio, vos organización social, me estás pidiendo plata para que yo Estado te financie una capacitación. Bueno, perfecto, ahora la capacitación que vas a dar le tiene que servir a esos sujetos para una posible y real inserción en una empleabilidad en el mercado. (...) Ellos al principio también querían darle mucho hincapié a lo que es la comercialización, creyendo que se encontraban con cooperativas que producían. (...) Pero, claro, cuando empiezan a charlar uno a uno con la gente, te hacen cincuenta ladrillos a gatas porque trabajan cuatro horas, porque no son expertos, porque no se formaron para ello y apenas están sobreviviendo con 4000 pesos.

(Funcionaria 5 MDSN).

Desde el oficialismo argumentan que esa separación entre cooperativas sustentables y precarias es real pero que no significa una desatención o el retiro de financiamiento de las últimas. Se trataría de una diferenciación que permite direccionar con mayor eficacia los recursos. Sumamos dos interpretaciones de funcionarios:

Hay análisis de los subsectores de esta economía con más posibilidades que otros. No hemos tomado una decisión que implicara decir a este subsector no lo acompañamos y a este sí. Vamos analizando caso a caso. Somos más cautelosos en unos que en otros. Eso es cierto. Hay algunos a los que les vemos más potencial.

(Funcionario 1 MDSN).

(...) desde el punto de vista de la orientación de los recursos no creo que necesariamente haya una discriminación positiva hacia la economía popular y negativa hacia la economía social. (...) Una empresa recuperada de obreros de clase media baja no queda excluida, no la sacan porque (...) no cumplen con el criterio de vulnerabilidad. (...) [Está] la Subsecretaría de Economía Popular que maneja formación y un programa allí como el Creer y Crear que es para proyectos integrales de alta escala. Claramente estás manejándote en un rango que está arriba de la base de la pirámide, de los más hechos torta de todos. (...) ahí la definición de 
la economía popular la queremos desacoplar de la idea de economía de los pobres, de los desclasados.

(Funcionario $7 \mathrm{MDSN}$ ).

La separación entre una economía popular concebida como una economía de subsistencia y una economía social comprendida como un tercer sector productivo también estuvo presente en los gobiernos kirchneristas. Existía un área como el PTA que aspiraba a conformar un sector autogestivo dinámico y sólido; pero también proliferaron planes como el Argentina Trabaja en el que no había mayores expectativas productivas y comerciales. El sujeto al que se dirigieron esas políticas sociales entre 2003 y 2015 era colectivo, de allí el requerimiento obligatorio de organizarse como cooperativa para obtener los planes.

Cambiemos pone fin a esa orientación. Utilizó parámetros mercantiles para detectar cooperativas subsidiadas con capacidades reales de sustentabilidad y empleabilidad y para el resto, consideradas inviables, implementó una medida decisiva: eliminó el requisito de crear cooperativas para obtener planes. $\mathrm{O}$ en otras palabras: los subsidios se transfirieren a trabajadores informales individuales. Entonces, más que una asignación más eficaz de los recursos, tal como afirma el "funcionario 1", lo que subyace en estas decisiones es una concepción política sobre cuál es el sujeto de la asistencia.

\section{Argentina cooperativa}

El PRIST se inició con el lanzamiento del Plan Argentina Trabaja (PAT) en 2009 y más tarde, en 2013, con una línea específica para mujeres en situación de alta vulnerabilidad social y ocupacional denominada Ellas Hacen (EH).

El PAT se implementa a través de la bancarización de los titulares. Los fondos son transferidos en forma directa y mensual por el MDSN, quien también asume los costos del monotributo social. Los beneficiarios son personas pertenecientes al segmento más persistente de desocupados e informales. Son aquellos que carecen justamente de ingresos formales en el grupo familiar, no cuentan con otras prestaciones, ni tampoco pensiones o jubilaciones, ni están cubiertos por otros planes sociales, a excepción del Plan de Seguridad Alimentaria (Hopp 2016). El PAT creó cooperativas de acuerdo a la Resolución 3026/06 del Instituto Nacional de Asociativismo y Economía Social (INAES), cuya planificación de actividades y proyectos de trabajo dependen de instancias ejecutoras de los distintos niveles gubernamentales (nacionales, provinciales y municipales).

Los Entes Ejecutores reciben transferencias desde el MDSN para varios fines, entre los que se incluye el pago de los gastos administrativos para inscribir y sostener las cooperativas de trabajo, la compra de materias primas, ropa de trabajo y herramientas, y se ocupan de la planificación de las labores a realizar a modo de contraprestación. ${ }^{4}$ 
Los primeros Entes fueron dependencias nacionales pero no pudieron sostenerse porque las cooperativas debían incluirse en obras de infraestructura federales de envergadura que requerían de una mano de obra calificada de la que carecían. En una segunda instancia se determinó que fueran las provincias, pero finalmente se optó por una generalizada municipalización debido a que la mayoría de los recursos estaban dirigidos al conurbano bonaerense (con más del 50\% de los beneficiarios).

De acuerdo a Natalucci y Kasparian (2012, 2017), la relación entre las organizaciones sociales y los municipios bonaerenses no estuvo exenta de intensos conflictos por la asignación del PAT. Las agrupaciones distantes desde un punto de vista político, del entonces gobierno nacional padecieron marginaciones. No se trató de un plan universal sino selectivo y focalizado, lo cual fomentaba "la discrecionalidad política más allá de la existencia de algunos controles institucionales" (Abramovich y Pautassi 2009:330).

En un documento de balance de la Jefatura de Gabinete de Gobierno (2015), se afirma que el PRIST en sus dos líneas -Ellas Hacen y Argentina Trabaja- incorporó entre 2009 y 2015 un total de 308.022 personas en situación de vulnerabilidad social en las provincias de Buenos Aires, Tucumán, Corrientes, Mendoza, Entre Ríos, Salta, Santiago del Estero, San Juan, La Rioja, Río Negro, Misiones, Chaco, Formosa, Catamarca, San Luis y Ciudad de Buenos Aires. Pero aclara que para 2015 tan solo 65\% de los cooperativistas se mantenían activos. El egreso del otro 35\% se debió, siempre desde lo afirmado en el documento, a la integración a empleos formales, a trabajos por cuenta propia, la inclusión en el sistema previsional o el mejoramiento económico de sus familias. El número total de cooperativas incubadas alcanzó a 7.999 (Jefatura de Gabinete 2015).

La pregunta insoslayable es por las razones por las que los gobiernos de Néstor Kirchner y Cristina Fernández eligieron la forma cooperativa para implementar sus políticas sociales y de empleo. Primero retomamos una hipótesis ya formulada en el análisis del PTA: impulsaron el asociativismo y la autogestión porque habían comprobado, a través de un pormenorizado estudio y acompañamiento, el relativo éxito que habían tenido los (micro)emprendimientos cooperativos sostenidos por las ERT y los movimientos de desocupados para contener a vastos sectores de la población expulsados por el mercado laboral. Pero debemos sumar otra complementaria: el objetivo de segmentar y reorganizar (en términos administrativos y de gestión) los territorios periféricos, sobre todo el conurbano bonaerense, a través de cooperativas subsidiadas.

El macrismo se apoyó inicialmente en esta forma de penetrar territorios complejos desde un punto de vista social, económico y laboral:

(...) el cooperativizar y estructurar en células ordenadas y aprehensibles ordenó el caos del territorio. Te ordenó una 
masa informe descontrolada o caótica que no la podías agarrar. Decir que vos sos de la cooperativa Néstor Vive de Florencio Varela, que son treinta personas con DNI, y que a Carlitos, o al puntero, al intendente, o al cura, o quien sea, le tocan estas cinco cooperativas, es una forma fantástica, muy lúcida, de ordenarte el territorio, lo que antes era la gente en general. Fue una genialidad que hoy nos permite que cualquier política pública que pensemos el primer grupo definido son las 200 mil personas del programa de transferencia condicionada.

(Funcionario 7 MDSN).

(...) las cooperativas, (...), en muchos lugares funcionan como una herramienta de gestión. Vos no podés gestionar a 260 mil personas. Si cada cooperativa está compuesta por 30 , se reduce 30 veces y te ordena. Vos llamás entonces al presidente de cada cooperativa y eso te ordena un montón. (Funcionario 3 MDSN).

En los próximos apartados se realizará un análisis de las dos principales rupturas instrumentadas por el gobierno nacional en sus dos primeros años de gestión: primero, la eliminación de la forma cooperativa como requisito para obtener los subsidios; segundo, el reemplazo de los municipios por las organizaciones sociales y las ONGs como nuevos Entes Ejecutores del Plan Argentina Trabaja.

\section{El fin de las cooperativas}

Si algo caracterizó al PRIST desde su nacimiento es que promovía una asociatividad forzada (Hopp 2015; Vuotto 2011; Lo Vuolo 2010). La condición para obtener los subsidios disponibles era organizarse obligatoriamente como cooperativas. En otras palabras, el sujeto de la política social era colectivo e, incluso, se forzaba su conformación como tal.

Cambiemos puso fin a ese requisito en 2016 en el caso de las nuevas altas. Si bien existió un intento de eliminar a las cooperativas preexistentes (pero sosteniendo el cobro individual mensual), la respuesta de los titulares en las provincias elegidas fue virulenta y se desistió.

A continuación es preciso analizar con detenimiento los diversos argumentos otorgados por funcionarios técnicos del MDSN para implementar este viraje.

La principal razón que se esgrime es que la asociatividad forzada impidió un genuino proceso cooperativo entre los titulares. 
(...) no podemos asociar la cooperativa a la participación en un programa de transferencia condicionada. Estar en una cooperativa es otro proceso, es otra decisión libre de las personas, vinculado a un proceso económico socio-productivo. El programa de transferencia condicionada no es un proceso de producción socioeconómica. Es un programa de restitución de derechos, de asistencia, de acompañamiento (...). Pero muy poquitas cooperativas generaron un proyecto real autogestionado en lo productivo, de servicios, etc. (...) Le dábamos el sello antes que el contenido, era como ponerle la etiqueta a un frasco vacío. Lo que necesitábamos era el dulce adentro (...). Eso requiere otro proceso, otro acompañamiento, otro desafío.

(Funcionario 1 MDSN).

(...) el máximo error es que vos no podés armar una cooperativa por decreto. Se armaron por decreto. Entonces ahí hay un error gravísimo. Porque (...) la gente no se reúne en conjunto y forma un colectivo de trabajo por decreto. (Funcionario $4 \mathrm{MDSN}$ ).

La medida apunta, desde la perspectiva del actual gobierno, a quitarle ese carácter forzado a los agrupamientos asociativos. Pero, ¿por qué se eliminó esta forma asociativa y no se pusieron en marcha procesos de capacitación o formas de acompañamiento capaces de promover dinámicas y valores cooperativos reales? Por el contrario, el gobierno incorporó criterios empresariales de evaluación de las cooperativas, lo cual generó una separación entre sustentables y prescindibles. El desenlace fue el pasaje de una política social dirigida a sujetos colectivos (aún si forzados en su origen), a una destinada a financiar individuos inmersos en una crítica situación social, económica, laboral y educacional.

Otros argumentos sobre las razones por las que se decidió eliminar las cooperativas surgen de las siguientes entrevistas a funcionarios:

Lo que sí hay (...) es un esfuerzo enorme por identificar a las cooperativas que genuinamente funcionan como tal $y$ tratar de pescar ahí y ver cómo incubarlas, acompañarlas. Hay un convenio con el Ministerio de la Producción para eso, con universidades para promover eso que incipientemente es una cooperativa de trabajo. Entonces no es un rechazo absoluto al cooperativismo sino lo que hay es un diagnóstico de que son cooperativas espúreas, cooperativas que son solo una 
formalidad para cobrar los programas y nada más.

(Funcionario $3 \mathrm{MDSN}$ ).

La cooperativa como forma legal, (...), no hay ninguna que funcione como tal (...). Es decir, no hay ninguna experiencia de cooperativas de 60 personas que haya funcionado $y$ dado un salto cualitativo en una producción y que puedan, por ejemplo, vender su producción afuera, en el mercado. Entonces, la forma de la cooperativa a ellos no se le suma [a los titulares], al gobierno le genera gastos, pues desarmemos las cooperativas y que sigan cobrando como titulares sueltos. (Funcionaria 5 MDSN).

Se suma un segundo argumento,íntimamente ligado a los anteriores, que pone el foco en el emprendedurismo, uno de los valores primordiales impulsados por la alianza Cambiemos.

(...) desde lo retórico se planteó muy fuerte esta cuestión del emprendedurismo. (...) La pregunta es si vos creés que la desocupación la resolvés con emprendedurismo individual o fomentando la industria para generar una captación media masiva de trabajadores. Son dos estrategias completamente distintas y me parece que la primera es la que suscriben los funcionarios actuales.

(Funcionario 3 MDSN).

Aún en el marco de su discurso sobre la necesidad de reducción del gasto público, el gobierno incrementó los subsidios a desocupados e informales. La apuesta mayor, según los testimonios recolectados, pasa por transformarlos en emprendedores individuales; $\mathrm{y}$ en menor medida colectivos en tanto deben cumplir con un requisito severo en el actual contexto económico e industrial: sustentabilidad financiera y capacidad de generar empleo. Un documento interno del MDSN (2018) afirma que en el cuarto trimestre de 2017 el total de titulares del PAT ascendió a 163.188, a los que sumaban 80.178 beneficiarias del programa Ellas Hacen y 17.638 titulares del programa Desde el Barrio (tercera línea del PRIST). El total de titulares fue entonces de 261.004.

Un tercer argumento, en este caso de carácter legal:

(...) los presidentes de las cooperativas están jugadísimos con la AFIP (Administración Federal de Ingresos Públicos) porque acumularon deudas con una normativa que no estaba clara. (...) hoy están obligadas a venderles al Estado 
porque para [hacerlo a] un privado tienen que pagar deudas de ochos años de impuestos. (...) Es por el IVA. Cuando le vendés al Estado tenés que pagar el 10,5\% en vez del $21 \%$, pero vos tenés que declarar mes a mes los diferenciales. Como le vendían todo el tiempo al Estado estaban permanentemente exentos, pero si vos no hiciste la declaración de exención al principio, cosa que casi ninguna hizo, en la cabeza del presidente hay una deuda fenomenal.

(Funcionario $3 \mathrm{MDSN}$ ).

Nuevamente, si una de las razones fue las deudas acumuladas por las cooperativas, se podría haber implementado un blanqueo que permitiera subsanar esas irregularidades impositivas.

En síntesis, Cambiemos afirmó con sus políticas la necesidad de subsidiar a la población más precaria de la Argentina en un contexto de caída del empleo, incluido del empleo informal en 2017 y con cierto repunte en 2017. El nuevo sujeto de la asistencia fue individual, con la excepción de las cooperativas sustentables desde un punto de vista empresarial.

En el último apartado, analizaremos la última ruptura implementada por el gobierno nacional: el reemplazo de los municipios como administradores del Plan Argentina Trabaja.

\section{El Triunvirato de la Economía Popular}

A partir de 2016 se decidió que los Entes Ejecutores de las nuevas altas del PAT pasaron a ser las organizaciones sociales y las ONGs. Así se lo fundamenta en un documento interno:

Se agregaron también en el semestre nuevos tipos de Entes Ejecutores, incluyendo Movimientos Sociales y Organizaciones No Gubernamentales, tanto para abordar proyectos específicos así como fomentar la posterior evaluación de eficacia relativa de cada Ente según su tamaño, dispersión de territorio y tipología. Se pasó de 118 Entes Ejecutores a comienzos de año, a 157 Entes confirmados a mediados de año. Al terminar el semestre se cuenta con el $80 \%$ de los nuevos convenios firmados y 65 planes de actividades aprobados.

(MDSN, 2016).

La medida no se aplicó en forma retroactiva, sólo incluyó los nuevos listados de beneficiarios y una mínima cantidad de casos en los que hubo un traspaso de planes desde los municipios a los movimientos, tal como ocurrió en Morón, provincia de Buenos Aires. 
Según datos oficiales, de un total de 30.061 nuevas altas otorgadas en 2016, 28.862 comenzaron a ser administradas por las organizaciones sociales (MDSN, 2016).

Esto significó que las agrupaciones recibieran en 2016 y 2017 relevantes transferencias de recursos (se estima 720 millones de pesos) por parte del MDSN para la compra de materiales, herramientas, maquinaria y otros insumos; a la vez que fueran ellas exclusivamente quienes decidieran las contraprestaciones a realizar por los titulares de los planes. A diferencia de los municipios, no recibieron fondos para la inscripción y sostenimiento de las cooperativas puesto que, como ya analizamos, se puso fin a esa figura como requisito para la obtención de los subsidios. Desde diciembre de 2015 se aumentaron los montos de cobro individual en tres oportunidades hasta llegar a los $\$ 4400$ actuales.

Un actor político clave en este nuevo esquema de gestión impuesto por el gobierno nacional fue en esta primera mitad del mandato la Confederación de Trabajadores de la Economía Popular (CTEP). La CTEP nació en 2011 con el objetivo de representar a una cada vez más expansiva masa de trabajadores informales. El diagnóstico sobre el fin de la sociedad salarial (Castel, 1997) fue su punto de partida. De esta forma lo analizan en un cuaderno de formación interna:

Estamos convencidos de que el capitalismo ha entrado en una nueva etapa, una etapa en la cual el trabajo asalariado ha dejado de ser la relación social predominante del sistema socioeconómico. (...). Las conquistas del movimiento obrero son casi piezas de museo, el patrimonio de una porción cada vez más pequeña de la clase trabajadora. La mayoría de nuestros compañeros no tienen un patrón que quiera comprar su fuerza de trabajo a cambio de un salario relativamente digno. (...) nuestros compañeros se inventaron su propio trabajo, allá en el barrio, (...), en las periferias olvidadas por todos.

(Pérsico y Grabois 2014:1).

Como en el caso de la Confederación General del Trabajo, ${ }^{5}$ el gobierno situó como interlocutor un triunvirato que llamaré de la economía popular: CTEP, Barrios de Pie y la Corriente Clasista y Combativa (CCC). ${ }^{6}$

Así caracteriza una funcionaria del Ministerio de Trabajo la relación que ha establecido Cambiemos durante los primeros dos años de su mandato con el Triunvirato:

A ellos no se les dice que no. Sus cooperativas llegan en paquete cerrado como parte de acuerdos políticos permanentes. 
Desde que se inició la gestión hay mucha permeabilidad a los planteos de las organizaciones, sobre todo algunas que tienen mucha capacidad de movilización. Hay bastante diálogo, eso es verdad, hay teléfono rojo permanente con muchas de ellas. Es con CTEP sobre todo (...).

(Funcionario 6 en el MDSN).

Esta posición privilegiada le permite a la CTEP fundamentalmente encarar dos procesos complementarios: en un contexto económico-laboral sombrío, robustecer sus estructuras a través de conflictos y acuerdos, y la incorporación a paso acelerado de organizaciones que deben sumarse a su ascendente estructura para obtener recursos estatales con mayor facilidad.

Un funcionario del PAT analiza esta situación:

Nosotros no tenemos cambios en el volumen [de subsidios]. Ya veníamos con un gran volumen [en 2016], sobre todo de cooperativas de organizaciones sociales. Este gobierno tiene (...) con la CTEP una mesa de diálogo. La CTEP cada vez se fue agrandando más, porque empezó el Movimiento [Evita], el MTE [Movimiento de Trabajadores Excluidos] $y$ algunas organizaciones más. Pero ahora las organizaciones se dieron cuenta que es el interlocutor al que más se lo escucha. En este contexto nosotros tuvimos que atender a un montón de cooperativas en situaciones que en otro momento no hubiéramos atendido.

(Funcionario 2 MTEySS).

El gobierno se propone contener posibles focos de protesta social en un escenario social económico y laboral recesivo estableciendo un triunvirato como interlocutor único a través del cual instrumentaliza las políticas sociales hacia los informales y desocupados. En las entrevistas los funcionarios lo afirman de la siguiente manera:

Es comprar gobernabilidad, es mucho pragmatismo. (...) con los planes de alguna manera para los sectores empresarios más duros es como decirles "sin esto no hay gobierno, no se sostiene políticamente, o vamos al conflicto permanente". (...) se le da mucha importancia a todo lo que es la protesta social. Se le tiene mucho respeto de alguna manera a eso. (Funcionario 3 MDSN). 
Me parece que es para reconstruir un nuevo orden, una nueva alianza desde donde apoyarse en los territorios. (...) Este es un gobierno que no tenía territorialidad. (...) me parece que este gobierno es muy consciente de su debilidad territorial y del empobrecimiento de las clases populares. (Funcionario $4 \mathrm{MDSN}$ ).

El punto máximo de acuerdo entre el oficialismo y el Triunvirato fue la aprobación de la Ley de Emergencia Social en diciembre de 2016. La 27.345 crea un Consejo de la Economía Popular y también el Salario Social Complementario (SSC) en la órbita del MDSN. Este último consiste en un complemento, equivalente al 50\% del Salario Mínimo,Vital y Móvil, a los ingresos mensuales que obtienen los trabajadores informales a través de sus emprendimientos. ${ }^{7} \mathrm{El}$ Consejo está compuesto por un representante del MTEySS, uno del MDSN, otro de Hacienda y Finanzas Públicas y tres miembros de las organizaciones sociales. Su principal tarea consiste en generar un registro nacional de trabajadores de la economía popular, que son quienes acceden al SSC.

Hasta diciembre de 2017 se utilizó el Programa de Transición hacia el SSC con el objetivo de unificar de manera ordenada en una misma figura y monto retributivo a los titulares de los múltiples planes sociales existentes en el MTEySS y en el MDSN. El presupuesto comprometido es de 25 mil millones con la posibilidad automática de adicionar otros 5 mil millones hasta 2019. Según documentos oficiales, hasta diciembre de 2017 el total de beneficiarios del SSC ascendió a 164.123 (MDSN, 2018).

Una hipótesis a introducir es que, de manera contraria a la figura del salario que utiliza la Ley, lo que se extiende y consolida es un monotributismo social. Es decir, se multiplican los trabajadores a los que se separa del salario, una tendencia inaugurada desde la aplicación de políticas neoliberales en materia laboral en la Argentina. Si bien no se trata de una tendencia que afecta solo a los segmentos más precarios (existen 3.100.000 monotributistas), sí se inscribe como un rasgo estructural de esta población excluida de manera estructural del mercado de trabajo formal.

El impulso en mayo de 2017 al Plan Empalme, una iniciativa que permite a los beneficiarios de programas sociales que consiguen un empleo seguir cobrando el SSC y a las empresas contabilizarlo como parte del sueldo neto, hasta el momento ha resultado negativo. "Se anunció con bombos y platillos pero no pasó nada relevante. Lo anunciaron como una transición desde la economía popular hacia la economía formal", admite el funcionario 4 del MDSN.

Si retomamos la aprobación de la Ley de Emergencia Social, debemos mencionar un inciso en el que, a cambio de la transferencia de recursos, las organizaciones se comprometían por escrito a abstenerse de todo tipo de conflictos y reclamos hasta el final del mandato del 
presidente Mauricio Macri. Se trató de un intento por formalizar el principal objetivo de Cambiemos: limitar y regular la protesta social a través de acuerdos con las organizaciones.

Nuestra hipótesis es la siguiente: a través de la Ley de Emergencia Social se institucionalizaron los acuerdos (no exentos de tensiones) entre el gobierno nacional y el Triunvirato de la Economía Popular. La conversión en Entes Ejecutores del PRIST, desplazando a los municipios, fue el antecedente inmediato.

Para un funcionario del MDSN la gobernabilidad está en el centro de este tipo de acuerdos en torno a los planes sociales:

Me parece que las políticas sociales del Ministerio de Desarrollo Social o las políticas más orientadas a empleo tienen más que ver desde mi perspectiva con (...) evitar el conflicto y generar gobernabilidad. (...) Sé que tiene más que ver con eso que con una mirada estratégica de construcción de inclusión, de construcción de ciudadanía. (...) creció el número de altas en el PRIST y en el Salario Social Complementario, pero sin una programación, por ejemplo. (Funcionario $6 \mathrm{MDSN}$ ).

La exclusión de los municipios da cuenta de un cálculo de Cambiemos sobre su situación política en las localidades más empobrecidas del conurbano bonaerense en la primera mitad de su mandato. Durante la anterior gestión también había permanentes conflictos y pactos con los movimientos sociales pero siempre mediados por los intendentes. Para el gobierno actual la institucionalización del vínculo con el Triunvirato es un aspecto clave porque lo interpretan como un eficaz dique de contención de la protesta social sin necesidad de negociación con intendencias opositoras.

La consistencia de estos acuerdos puede inferirse de la entrevista siguiente:

(El Triunvirato de la Economía Popular) va a seguir haciendo el juego que históricamente hicieron los sindicatos, presionan y después hacen su juego político propio. (...) no es afin a este gobierno pero le saca todo lo que puede. Cosa que además a mí si yo fuera del PRO estaría preocupado porque vos estás empoderando mucho a una organización con una capacidad territorial enorme, enorme, $y$ te van a jugar en contra.

(Funcionario 4 MDSN). 
Se suma un aspecto clave que introduce un funcionario del MDSN en el que advierte que la perdurabilidad del vínculo entre el gobierno y el Triunvirato está más ligada a cuestiones políticas que presupuestarias:

Creo que esa relación cercana entre el gobierno y las organizaciones va a seguir pero más condicionada a la evolución del vínculo político que a una necesidad fiscalista. Creo que van a seguir los planes sociales y eventualmente sí puede ocurrir que haya un giro como con los gremios grandes. "Ah, sí, me enfrestaste, entonces tomá, te echo a estos dos o saco esto que te daba" (Funcionario 7 MDSN).

Finalmente, otro integrante de ese ministerio abre interrogantes sobre la relación entre las bases sociales y la CTEP. Se destaca un progresivo debilitamiento de la representación lograda por esta Confederación en los barrios periféricos.

Yo creo que nunca va a haber ruptura con ellos. Ninguno de los dos actores se puede dar el lujo (...). Sí es una relación que se basa en el conflicto natural de fuerzas. También creo que la gente en los territorios está mucho más madura en algún sentido. Creo que se encolumnó tras de CTEP porque la vio como un interlocutor válido. Pero su vínculo con CTEP es muy nuevo. Después muchas personas tienen su adscripción a pequeños grupos muchos más territoriales, mucho más específicos. Para mí lo que está en juego es la idea del gran articulador de las bases territoriales, que es lo que CTEP se propuso. (Funcionario 1 MDSN).

En el primer testimonio las estrategias del Triunvirato se emparentan con las formas más tradicionales de los grandes sindicatos; en el segundo se revelan los eventuales disciplinamientos por parte del gobierno en el caso de que el Triunvirato enfrente abiertamente sus políticas en las calles, lo cual vislumbra un futuro incierto; y en el tercero, se reafirman las conveniencias mutuas entre el gobierno y CTEP pero se abre un sugerente interrogante en torno a la relación entre este tipo de organizaciones territoriales con sus bases. 


\section{Conclusiones}

En el período 2003-2015 se crearon 5 millones de puestos de trabajo, según datos oficiales. Sin embargo, en paralelo, fue indispensable construir una sólida estructura de políticas de subsidios al cooperativismo para impulsar el empleo y la inclusión social entre los desempleados e informales crónicos. La hipótesis inicial del artículo fue que, una vez comprobados los límites en la generación de empleos formales, se pusieron en marcha estrategias de generación de ingresos que denominamos post-salariales con el asociativismo como epicentro.

Para comprender las continuidades y rupturas a partir de la asunción de la alianza Cambiemos en diciembre de 2015, se llevó a cabo un minucioso análisis del Programa de Trabajo Autogestionado y también del Programa de Ingreso Social con Trabajo entre 2016 y 2017.

Desde su creación, el PTA se propuso como objetivo principal la incipiente gestación de un tercer sector en base a empresas recuperadas por trabajadores, la formalización de proyectos asociativos preexistentes y, por último, el proyecto más ambicioso: el impulso de emprendimientos cooperativos incubados por la propia área. A través de la inyección de fondos y la creación de redes sectoriales se intentó tornar sustentables a las cooperativas para que pudieran operar con respaldos financieros elementales en sus respectivos mercados.

El impulso al PRIST tuvo otra motivación diferente. Su misión fue forzar asociaciones cooperativas entre los calificados como inempleables por el mercado de trabajo. Para este tipo de emprendimientos asociativos no existieron mayores expectativas sobre su capacidad de producción y comercialización, puesto que se los redujo a prestatarios de servicios en los municipios. La intención prioritaria fue que funcionaran como canales de transferencia de recursos dirigidos a poblaciones informales y desempleadas crónicas.

Una conclusión es que durante el kirchnerismo estas políticas públicas surgieron como efecto de investigaciones sistemáticas llevadas adelante por el MTEySS y el MDSN sobre los modos específicos de autogestión sostenidos por las ERT y las organizaciones de desocupados. El paso siguiente fue la progresiva traducción al lenguaje gubernamental de esas estrategias colectivas sostenidas por los movimientos durante la crisis de inicios de este siglo. De esta manera se promocionaron nuevos emprendimientos asociativos ya con un modelo asociativo estatal propio. La otra razón por la que se forzó a los sectores informales a formar cooperativas para obtener subsidios, fue la imperiosa necesidad política de organizar y tornar aprehensible poblaciones y territorios complejos como el conurbano bonaerense.

La alianza Cambiemos encontró en el MTEySS y el MDSN estas sólidas estructuras administrativas que les permitieron el acceso a esas periferias en donde el empleo en blanco es mayormente un recuerdo de otras generaciones. En contraposición de los análisis más maniqueos sobre el nuevo gobierno, no sólo no hubo recortes en los primeros dos años 
de gestión sino que se incrementaron los presupuestos del PTA y el PRIST. Pero dichos aumentos coincidieron con una masiva demanda de ayuda financiera de las cooperativas en un contexto social, laboral, económico y financiero recesivo provocado por sus propias políticas; lo mismo ocurrió en el caso de aquellas poblaciones que, mediante las organizaciones sociales, reclamaron masivamente su ingreso al PRIST como paliativo a la caída de sus ingresos informales en el marco de un mercado interno en permanente retroceso.

Otra conclusión, en este sentido, es que el actual gobierno, a pesar de sus diferencias políticas, ideológicas y programáticas con las tres administraciones del período 2003-2015, consideró de vital importancia política en su primera mitad de mandato fortalecer este tipo de programas basados en la autogestión cooperativa para la contención de los sectores más precarios.

En lo que respecta a las rupturas, Cambiemos inició desde su asunción un relevamiento sobre la sustentabilidad de las cooperativas subsidiadas. Los criterios aplicados fueron únicamente empresariales. En otras palabras, se evaluó si los emprendimientos lograban insertarse en sus mercados correspondientes y si tenían capacidad de generar empleo. El resultado de ese relevamiento fue la eliminación del requisito de organizarse en cooperativas para obtener los subsidios en el PRIST. El argumento excluyente fue que esos emprendimientos nunca lograron un funcionamiento cooperativo real y que, salvo excepciones, tampoco dar un salto mínimo de productividad y competitividad. Para los casos minoritarios en los que se comprobaron capacidades reales de producción, comercialización y empleabilidad, se crearon áreas como la Subsecretaría de Economía Popular en el MDSN y se fortaleció la capacidad de financiamiento del PTA en el MTEySS.

El kirchnerismo, vale mencionarlo, también separaba entre organizaciones competitivas y de subsistencia. Sin embargo no decidió, como sí lo hizo el actual gobierno, eliminar la forma cooperativa como principio rector de esas políticas. Allí radica una diferencia sustancial: si entre 2003 y 2015 las políticas sociales se dirigían principalmente hacia sujetos colectivos, incluso forzando las agrupaciones mediante la forma cooperativa, el macrismo las concibe como una contención financiera mínima a sujetos individuales, que pretenden que se transformen en emprendedores.

La otra medida de ruptura fue el reemplazo de los municipios por las organizaciones sociales como Entes Ejecutores del PRIST. Se trató del antecedente inmediato a la aprobación parlamentaria de la Ley de Emergencia Social. Para comprender esta decisión fue indispensable incluir, desde la perspectiva del gobierno, el rol que cumplió entre 2016 y 2017 un actor clave en la instrumentalización de los planes sociales: el Triunvirato de la Economía Popular, compuesto por CTEP, Barrios de Pie y la CCC. La conclusión es que la Ley de Emergencia Social tuvo como objetivo para Cambiemos la institucionalización de los acuerdos que ya venían desarrollándose con estas organizaciones sociales. El gobierno se propuso formalizar por escrito pactos con el Triunvirato 
en la medida en que lo consideró un actor indispensable para en el inicio de su mandato para la gestión de los subsidios. O en otras palabras, para la contención de la protesta social de los sectores informales de la economía.

Los funcionarios del PTA y el PRIST entrevistados afirmaron que CTEP, Barrios de Pie y CCC han tenido en 2016 y 2017 la prioridad exclusiva en la obtención de subsidios y planes, lo cual les permitió robustecer sus estructuras organizativas y la absorción de organizaciones que requieren de su amparo para garantizar la obtención de recursos.

Por su parte, la Ley de Emergencia Social creó una figura: el Salario Social Complementario. La paradoja es que, lejos de reponer la figura del asalariado, se limita, por el contrario, a trasferencias mensuales no remunerativas hacia trabajadores que justamente padecen de manera estructural la imposibilidad de acceso a un empleo en blanco. Una conclusión es que con sus políticas en materia de empleo y de subsidios, Cambiemos promueve lo que denominamos un monotributismo social, definido como una separación estructural entre empleo y salario.

A partir estas múltiples dimensiones contextuales y analíticas es que podemos comprender con mayor precisión las razones por las que el gobierno nacional ha fomentado en 2016 y 2017 la economía social y popular entre los sectores informales habitantes de los territorios urbanos periféricos. 
${ }^{1}$ En el último documento publicado por el PTA se enumeran dieciocho jornadas sobre empresas autogestionadas con las ERT en ese período (MTEySS 2015).

${ }^{2}$ Dato extraído del informe Trabajo y Empleo en el bicentenario. http://www.trabajo.gov.ar/left/estadisticas/bicentenario/Texto_Publicacion_TRABAJO_Y_EMPLEO_EN_EL_BICENTENARIO.pdf accesado 29 de agosto de 2017.

${ }^{3}$ La línea 1 de ayuda económica individual "tiene como objetivo brindar apoyo en la fase de inicio de las actividades o cuando atraviesen situaciones críticas (...) El programa asiste a los trabajadores de las unidades productivas autogestionadas mediante la asignación de una ayuda económica mensual (...) por cada trabajador durante un período máximo de doce meses (...)".http://www.baseinstrumentos.mecon.gob.ar/imprimir. php?imprimir=S\&id_prog=2753 accesado 5 de abril de 2018 .

${ }^{4}$ Los Entes Ejecutores son las unidades administrativas a través de las cuales se aplica el Programa de Ingreso Social en los territorios. El Ministerio de Desarrollo Social transfiere los fondos financieros indispensables para el sostenimiento legal de las cooperativas y para la compra de materias primas y ropa de trabajo de sus integrantes. ${ }^{5}$ Luego de fracturarse en 2011, los sindicatos que integran la Confederación General del Trabajo, el principal órgano de representación de los trabajadores asalariados en la Argentina, decidieron en 2016 reunificarse y fijar un triunvirato en la conducción. Desde entonces son esos tres dirigentes los encargados de los diálogos y las negociaciones con el gobierno nacional.

${ }^{6}$ Barrios de Pie es un movimiento social creado en 2001. Se trata del brazo territorial del Movimiento Libres del Sur. La Corriente Clasista Combativa (CCC) es una agrupación política territorial y sindical creada en 1994 por el Partido Comunista Revolucionario.

${ }^{7}$ La obtención del SSC no es complementaria con otros planes sociales. Tiene estrictas condiciones, todas basadas en la ausencia de ingresos formales en el ámbito estatal y privado. 


\section{Referencias bibliográficas}

Abramovich, Victor y Laura Pautassi (comps) (2009) La revisión judicial de las políticas sociales. Buenos Aires: Editores del Puerto.

Allegrone, Verónica, Inés Fernández Álvarez y Florencia Partenio (2007) Pensando en los dilemas de la autogestión en los procesos de recuperación de empresas y fábricas. http://www.aacademica.Org/000-106/162 accesado 15 de agosto de 2017.

Cafardo, Analía y Paula Domínguez Font (2003) Autogestión obrera en el siglo XXI: Cambios en la subjetividad de los trabajadores de empresas recuperadas, el camino hacia una nueva sociedad. Buenos Aires: Centro Cultural de la Cooperación.

Castel, Robert (1997) La metamorfosis de la cuestión social. Buenos Aires: Ed. Paidos.

Coraggio, José Luis (2011) Economía social y solidaria. El trabajo antes que el capital. Quito: Ediciones Abya - Yala.

Colectivo Situaciones (2009) Conversaciones en el Impasse. Dilemas políticos del presente. Buenos Aires: Tinta Limón.

Dávalos, Pablo (2011) "Hacia un nuevo modelo de dominación política: violencia y poder en el posneoliberalismo". En Raquel Gutiérrez (comp.) Palabras para tejernos, resistir y transformar en la época que estamos viviendo. Cochabamba:Textos Rebeldes, pp. 117-145.

De Sena, Angélica y Florencia Chahbenderian (2012) "Argentina, ¿trabaja?" http://polis.revues.org/2136;DOI: 10.4000/polis.2136 accesado 9 de septiembre 2017.

Deux Marzi, Victoria y Martín Escobedo (2005) Autogestión obrera en la Argentina: historia y presente. Rosario: UNR Editora.

Fajn, Gabriel (2003) Fábricas y empresas recuperadas. Protesta social, autogestión y rupturas en la subjetividad. Buenos Aires: Instituto Movilizador de Fondos Cooperativos.

Fernández, Ana María (2006) Política y Subjetividad. Asambleas barriales y fábricas recuperadas. Buenos Aires:Tinta Limón Ediciones.

Fornillo, Bruno (2008) "Derivas de la matriz nacional popular: el pasaje de la movilización a la estatización del Movimiento Barrios de Pie durante el kirchnerismo (2001-2007). En Sebastián Pereyra, Gastón Pérez y Federico Schuster (comps.) La huella piquetera.Avatares de las organizaciones de desocupados después de 2001. Buenos Aires: Ediciones Al margen, pp. 183-203. 
Giraudo, Carina (2013) Las cooperativas del programa Argentina Trabaja y la generación del trabajo genuino. Un estudio reflexivo sobre las nuevas formas de conceptualización del trabajo cooperativo. http://cdsa.aacademica.org/000-038/667.pdf accesado 5 de septiembre de 2017.

Gracia, María y Sandra Cavaliere (2007) “Repertorios en fábrica: la experiencia de recuperación fabril en Argentina, 2000-2006”. Revista Estudios Sociológicos 73:155-186.

Heller, Pablo (2004) Fábricas recuperadas. Argentina 2000-2004. Buenos Aires: Ediciones Rumbos.

Hintze, Susana (2007) Políticas sociales argentinas en el cambio de siglo. Conjeturas sobre lo posible. Buenos Aires: Espacio Editorial.

Hopp, Malena Victoria (2016) "Potencialidades y límites del programa Argentina Trabaja en dos barrios populares del conurbano bonaerense". DAAPGE. 27:7-35.

Hopp, Malena Victoria (2015) "Identidades laborales de destinatarios del Programa Ingreso Social con Trabajo Argentina Trabaja”. Revista Trabajo y Sociedad 24:207-223.

Hudson, Juan Pablo (2011) Acá no, Acá no me manda nadie. Empresas recuperadas por obreros 2000-2010. Buenos Aires:Tinta Limón Ediciones.

Hudson, Juan Pablo (2011) Empresas Recuperadas por los Obreros: Fin de Etapa y Nuevas Instituciones.http://webiigg.sociales.uba.ar/empresasrecuperadas/PDF/PDF_05/ hudson2.pdf accesado el 20 de septiembre de 2017.

Hudson, Juan Pablo (2016) "Políticas públicas y empresas recuperadas por sus obreros en Argentina. Un análisis del Programa de Trabajo Autogestionado 2004-2012”. Apuntes. Revista de Ciencias Sociales 79:157-184.

Hudson, Juan Pablo (2017) "Gobiernos progresistas y autogestión en la Argentina 2003-2015: cooperativas antiestatales, sintéticas y anfibias”. Revista Latinoamericana de Estudios del Trabajo 34:91-122.

Kasparian, Denise (2017) "De la inducción estatal a la cooperativa sin punteros. El conflicto constituyente en una cooperativa del Programa Argentina Trabaja”. http://publicaciones.sociales.uba.ar/index.php/argumentos/article/view/2539 accesado 3 de abril de 2018.

Jefatura de Gabinete de Ministros de la Nación (2015) Memoria detallada del Estado de la Nación 2013. http://www.desarrollosocial.gob.ar/wp-content/uploads/2016/09/ Memoria-del-Estado-de-la-Nacion-2015.pdf accesado 25 de agosto de 2017. 
Lo Vuolo, Ruben (2010) "El programa “Argentina Trabaja” y el modo estático de regulación de la cuestión social en el país”. http://www.ciepp.org.ar/trabajo.htm accesado 4 de agosto de 2017.

Massetti, Astor (2009) La década piquetera. Acción colectiva y protesta social de los movimientos territoriales urbanos. Buenos Aires:Trilce.

Magnani, Esteban (2003) El cambio silencioso. Empresas y fábricas recuperadas por los trabajadores en la Argentina. Buenos Aires: Prometeo.

Malandra, Andrés. (2013) "Continuidades y rupturas en la política social argentina: Argentina Trabaja”. http://www.memoria.fahce.unlp.edu.ar/tesis/te.952/te.952.pdf accesado 25 de julio de 2017.

Maneiro, María (2015) "Representaciones sociales sobre el Programa Argentina Trabaja en las clases populares urbanas”. Revista Katálysis 18:62-73.

Ministerio de Desarrollo Social (2016) Informe Primer Semestre 2016. Buenos Aires: Ministerio de Desarrollo Social.

Ministerio de Desarrollo Social (2018) Sistema de Indicadores Sociales (Resumen). Buenos Aires: Ministerio de Desarrollo Social.

Natalucci, Ana (2012) "Políticas sociales y disputas territoriales. El caso del programa Argentina Trabaja”. Revista de Perspectivas de Políticas Públicas 3:126-147.

Natalucci, Ana (2014) "La recreación de la gramática movimientista de acción colectiva: movimientos sociales y nuevas institucionalidades". En Pablo Forni y Luciana Castronuevo (comps.) Ni piqueteros ni punteros: organizaciones populares durante el kirchnerismo. La Plata: Edulp, pp.149-166.

Perelmiter, Luisina (2010) "Militar el Estado. La incorporación de movimientos sociales de desocupados en la gestión de políticas sociales. Argentina (2003-2008)". En Ernesto Villanueva, Astor Massetti y Marcelo Gómez (comps.), Movilizaciones, protestas e identidades políticas en la Argentina del bicentenario. Buenos Aires: Lugar, pp.132-152.

Perelmiter, Luisina (2016) Burocracia plebeya. La trastienda de la asistencia social en el estado argentino. Buenos Aires: Unsam Edita.

Pérsico, Emilio y Juan Grabois (2014) Nuestra realidad. Cuaderno 1 de formación para trabajadores, militantes, delegados y dirigentes de organizaciones populares. Buenos Aires: CTEP. 
Pico, Juan Manuel (2015) "10 años del Programa Trabajo Autogestionado. Resultados y Perspectivas”. http://www.aset.org.ar/2015/ponencias/11_Pico.pdf accesado 24 de marzo de 2018.

Ministerio de Trabajo, Empleo y Seguridad Social (2004) Programa de Trabajo Autogestionado. Informe anual. Buenos Aires: MTEySS.

Ministerio de Trabajo, Empleo y Seguridad Social (2010) Programa de Trabajo Autogestionado. Informe anual. Buenos Aires: MTEySS.

Ministerio de Trabajo, Empleo y Seguridad Social (2013) Programa de Trabajo Autogestionado. Informe anual. Buenos Aires: MTEySS.

Ministerio de Trabajo, Empleo y Seguridad Social (2015) Programa de Trabajo Autogestionado. Informe anual. Buenos Aires: MTEySS.

Programa Facultad Abierta (2010) Informe del Tercer Relevamiento de Empresas Recuperadas por sus trabajadores. Buenos Aires: Universidad de Buenos Aires.

Programa Facultad Abierta (2014) Informe del Tercer Relevamiento de Empresas Recuperadas por sus trabajadores. Buenos Aires: Universidad de Buenos Aires.

Rajland, Beatriz y Daniel Campione (2006) "Piqueteros y trabajadores ocupados en la Argentina de 2001 en adelante. Novedades y continuidades en su participación y organización en los conflictos". En Gerardo Caetano (comp.) Sujetos sociales y nuevas formas de protesta en la historia reciente de América Latina. Buenos Aires: Clacso, pp. 297-330.

Rebón, Julián (2004) Desobedeciendo al desempleo. La experiencia de las empresas recuperadas. Buenos Aires: Picaso/La rosa blindada.

Rebón, Julián (2007) La Empresa de la Autonomía. Trabajadores recuperando la producción. Buenos Aires: Colectivo Picaso.

Sader, Emir (2008) Refundar el Estado. Posneoliberalismo en América Latina. Buenos Aires: Instituto de Estudios y Formación de la CTA.

Sader, Emir (2012), "Posneoliberalismo en Brasil”. América Latina en Movimiento 475:4-8.

Salgado, Rodrigo (2012) “Los Límites de la Igualdad. Cambio y reproducción social en el proceso de recuperación de empresas por sus trabajadores"http://catalogosuba.sisbi.uba.ar/vufind/ Record/http\%253A\%252F\%252Fwww.sociales.uba.ar\%252Ftesis\%252FASO00000463 accesado 4 de julio de 2017. 
Schuttenber, Mauricio (2014) "El campo nacional y popular durante el kirchnerismo: una aproximación a las diferentes experiencias históricas, identidades y tradiciones políticas que reconfiguraron ese espacio desde el 2003”. En Pablo Forni y Luciana Castronuevo (comps.) Ni piqueteros ni punteros: organizaciones populares durante el kirchnerismo. La Plata: Edulp, pp. 99-127.

Svampa, Maristella (2003) “Cinco Tesis sobre la nueva matriz popular” http://www. insumisos.com/lecturasinsumisas/Cinco\%20Tesis\%20sobre\%20la\%20nueva\%20matriz\%20popular.pdf accesado 19 de septiembre de 2017.

Svampa, Maristella (2005) La sociedad excluyente. Buenos Aires: Taurus.

Svampa, Maristella y Sebastián Pereyra (2004) Entre la ruta y el Barrio: Las organizaciones piqueteras. Buenos Aires: Biblos.

Pereyra Sebastián, Germán Pérez y Federico Schuster (comps.) (2008) La Huella piquetera. Avatares de las organizaciones de desocupados después del 2001.

Buenos Aires: Ed. Al Margen.

Vuotto, Mirta (2011) El cooperativismo de trabajo en la Argentina: contribuciones para el diálogo social. , Lima: Programa Regional para la Promoción del Diálogo y la Cohesión Social en América Latina. OIT.

Zibechi, Raúl (2008) Territorios en resistencia. Cartografía política de las periferias urbanas latinoamericanas. Buenos Aires: La Vaca.

\section{Cómo citar este artículo:}

Hudson, Juan Pablo (2018) "Políticas públicas de promoción de la autogestión cooperativa de la alianza Cambiemos, 2016 y 2017”. Revista Perspectivas de Políticas Públicas vol. 8 No15: 173-205 